\title{
PALEOVALLEYS MAPPING USING REMOTE SENSING
}

\author{
A.B. Baibatsha \\ Kazakh National Technical University named after K.I. Satpayev, Almaty, Kazakhstan - baibatsha48@mail.ru
}

KEY WORDS: Space image, Interpretation, Paleovalleys, Ore-controlling structure, Groundwater resources

\begin{abstract}
:
For work materials used multispectral satellite imagery Landsat (7 channels), medium spatial resolution (14,25-90 m) and a digital elevation model (data SRTM).For interpretation of satellite images and especially their infrared and thermal channels allocated buried paleovalleys pre-paleogene age. Their total length is $228 \mathrm{~km}$. By manifestation of the content of remote sensing paleovalleys distinctly divided into two types, long ribbon-like read in materials and space survey highlights a network of small lakes. By the nature of the relationship established that the second type of river paleovalleys flogs first. On this basis, proposed to allocate two uneven river paleosystem. The most ancient paleovalleys first type can presumably be attributed to karst erosion, blurry chalk and carbon deposits foundation. Paleovalleys may include significant groundwater resources as drinking and industrial purposes. Also we can control the position paleovalleys zinc and bauxite mineralization area and alluvial deposits include uranium mineralization valleys infiltration type and placer gold. Direction paleovalleys choppy, but in general they have a north-east orientation, which is controlled by tectonic zones of the foundation. These zones are defined as the burial place themselves paleovalleys and position of karst cavities in areas interfacing with other structures orientation. The association of mineralization to the caverns in the beds paleovalleys could generally present conditions of formation of mineralization and carry it to the «Niagara» type. The term is obviously best reflects the mechanism of formation of these ores.
\end{abstract}

\section{INTRODUCTION}

For work we used materials of multispectral satellite imagery Landsat (7 channels) medium spatial resolution $(14,25-90 \mathrm{~m})$ and a digital elevation model (data SRTM).

Initial data for the performance of work were:

- Archival materials of multispectral satellite imagery Landsat. Shooting was executed in 27.04.2001. Spectral ranges channels are: PAN - 520-900 nm, 1 - 450 - $515 \mathrm{~nm}, 2$ - 525-605 nm, 3 630-690 nm, 4 - $750-900 \mathrm{~nm}, 5$ - 1550-1750 nm, 6 - 10400$12500 \mathrm{~nm}, 7-2090-2350 \mathrm{~nm}$. The spatial resolution of images is $14.25 \mathrm{~m}$ for PAN channel, $30 \mathrm{~m}$ for $1,2,3,4,5$ and 7 channels and $60 \mathrm{~m}$ for 6 channels (Figure 1). Landsat archive materials are taken on the site of Marilend State University (USA): http://glcfapp.glcf.umd.edu:8080/esdi/index.jsp;

- A digital elevation model (spatial resolution $90 \mathrm{~m}$ ) is taken on the site of the University of Maryland (USA): http://glcfapp.glcf.umd.edu:8080/esdi/index.jsp.

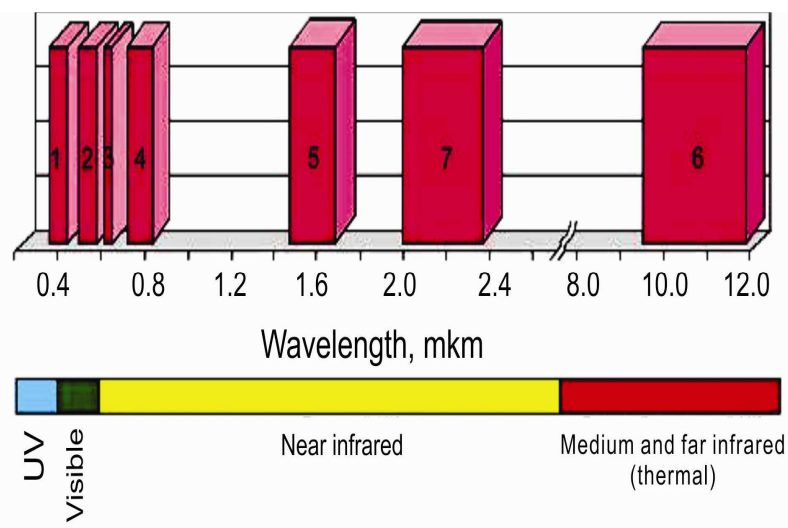

Figure 1. Spectral characteristics of the Landsat system space

\section{GEOLOGICAL DEVELOPMENT HISTORY OF AREA}

\subsection{Geological history}

Prospects for the study area for the presence of hidden industrial mineral deposits along with petrographic, mineragenous, tectonic and magmatic features and prerequisites, also closely connected with the history of its geological development (Uzhkenov, 2002).

In the Jurassic period and partly in the Early Cretaceous there are peneplanation of country continues further and strong weathering crust forms (Baibatsha, 2012). Weathering crust developed over the different ages and mineralogical compositions rocks at the same time. Weathering processes occurring in the humid and hot climate, have contributed to deep chemical transformation of source rocks, often to their stage of full kaolinization.

In Early Jurassic the Torgay depression begins general subsidence and its local parts go down more intensive in the axial part of the basin where Jurassic coal-bearing sediments accumulate. Study area was on the border between subsidence and jutting sections.

The first major post-Paleozoic sediments accumulation refers to the Aptian-Albian time, which is characterized by the accumulation of wide occurrence in continental conditions. Currently, deposits of this age are known only in certain areas dedicated to the pre-Cretaceous relief depressions, because Cretaceous and Cenozoic transgressions waters erode their.

Within the area little is known about sediments of Upper Cretaceous, except for the Maastrichtian shallow sands formed in marine environments. However, we can assume that the western part of the territory was the land in this time. At the same time the similar climate condition was in the eastern part. There continental regime changes marine sedimentation cycle after the Cenomanian, it was caused by lowering the overall territory Torgay depression. Marine regime exist almost the entire Last Cretaceous and Paleogene until the middle 
Oligocene with a small break in the Danish and Paleocene time. In this time the north- western part of Torgay depression was an area of erosion, as well as other areas of the trough.

By the early Middle Eocene whole Torgay deflection experienced the most significant subsidence. This led to flooding of its waters Tasaranskoye Sea. Sea coast line located just west of $61^{\circ}$. Sand and clay soils accumulate in coastal areas of the Tasaranskoye Sea, in the more remote parts of the deepwater flasks, and tripol opoka clays.

At the beginning of the Last Eocene was expanding the boundaries of pre-existing marine basin, here began transgression of Chaganskoye Sea. In the north- western part of the Torgay deflection a brief pause existed from time to time between Tasaranskoye and Chaganskoye times. Interruption was caused apparently crustal uplifts. Sediments of Tasaranskoye Sea blurred in large part. Now they are found as small plots, which covered by Chagansky deposits.

Again the crustal uplifting in the middle Oligocene made forever retreat the sea from the north-western part of the Torgay region. In middle Oligocene this part of area was a marine plain with plenty of residual lakes of various sizes, marshes and wide river valleys. The hydrographic network of that time was directed from west to east. Calcareous sands, clays, aleurites deposited in many reservoirs. In some parts of this accumulative area were created conditions favorable for the iron ore and lignite formations.

In upper Oligocene time continued accumulation of sediments with the partial revival of erosion activity. At the bottom of reservoirs deposited coarse-grained sands with pebbles. At this time, there was a partial erosion of some sections of the Mesozoic peneplain. River continued migrate widely, blurring the weathering crust and marine sediments of Cretaceous, Paleogeneand middle Oligocene. There formed alluvial sediments. Also there were small closed basins, and clays accumulated here as a result of erosion process of the weathering crust. Relics of these basins are fixed in the northeastern part of the area.

In the early Miocene physical and geographical conditions and climate may be abrupt change.

In the investigated area (Torgay deflection and adjacent areas West Siberian Plain and Northern Aral region) the closed salty pools appearance, they have various sizes. Heregypsum and green variegated clays accumulated, and quartz sand precipitated in some flowing water pools. Position of river network this time is unknown. May be the river network had latitudinal or north-east direction.

In the late Miocene and early Pliocene is a reorganization of the river network with laying the river valleys of modern shapes. The reason for this is obviously a rise in the Ural-Tau zone and adjacent areas. This is confirmed by the presence of ancient river valleysthat cut into the Aral suite sediments. Second reason is high terrace of Tobol River. Here was found redeposited Oligocene fauna in sediment.

Until we have not known about the geological changes during the early Quaternary. Presumably during this period the river network reconstructed, and possibly brown calcareous clay and loam accumulated in some areas.
Riss glacier came from the north at the beginning of the Pleistocene, though it did not reach to our works area, but it significantly influenced the formation of its relief (Abdullin, 1984). Glacier raised erosion base of all rivers to maximum limit, with their heavily flooded. Wandering over a wide area, the river developed a tremendous Torgaysky plain or low erosion surface alignment. Thick covering loam formed as a result the activity of these numerous rivers.

Lake District can be considered as relic. Many of them are located in the watersheds are located within previously existing river valleys.

\subsection{Deciphering, identification and interpretation of structures}

Technological scheme of decoding digital materials space survey is shown in Figure 2.

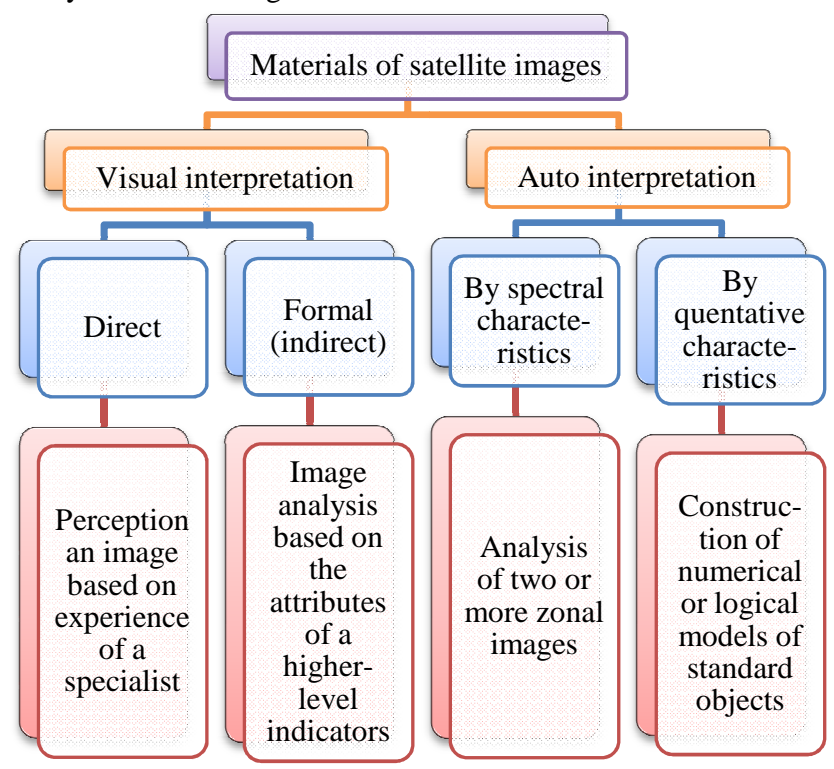

Figure 2. Technological scheme of digital decoding of satellite images (by Serokurov et al, 2001)

In this scheme visual interpretation is the most traditional method in geology. Classification methods of visual interpretation of remote sensing data is based on two approaches: direct (direct interpretation) - recognition on targets preparations, processes and phenomena by geological experts, and formal (indirectly) with the release of point, line, arc, circular and polygonal elements on the earth's surface over colortone, texture, luminance and other characteristics with subsequent grading, statistical processing, qualitative and quantitative evaluation, linking to geological structures and objects (Pertsova, 2000).

Direct interpretation presupposes that specialist has knowledge of geology of the study area and is often reduced to clarify the boundaries mapped by other methods (mainly land) of geological objects.

Formal visual interpretation of the first stage is limited recognition and fixation of landscape or thermal inhomogeneities. And relieve the operator from the ideological framework of geological models adopted in this area or in its organization. But as a rule, a formal interpretation in its pure form is not found (works here, apparently, known many geologists rule: «you see what you know»), experience and specialist knowledge play a decisive role. In this regard, the 
ability to completely formal decoding in the formal visual interpretation is in serious doubt, although this trend and looks attractive because it allows to exclude the subjective factor. In the work on decoding are typically used two approaches.

Interpretation results of bit maps at the last stage were filtered on the basis of available geological and geophysical data. Package of the accounting information included layers of interpretation results that contain the entire set of linear, circular, and area of geologic structure.

\subsection{Paleovalleys}

During interpretation of satellite images and especially their infrared and thermal channels are allocated buried paleovalleys (Potseluyev, 2011). Their total length is 228 kilometers. By manifestation of the content of remote sensing paleovalleys distinctly divided into two types: the first type - rather broad (600-3500 m), ribbon-like fragments are read only in the materials space survey; the second type - narrow (300-900 m), long ribbon-like are read in materials of space survey and high lights a network of small lakes (Figure 3). By the nature of the relationship established that the second type of river paleovalleys flogs first. On this basis, proposed to allocate two uneven river paleosystem.

The most ancient paleovalleys first type can presumably be attributed to karst erosion, blurry chalk and carbon deposits foundation. Paleovalleys may include significant groundwater resources as drinking and industrial purposes. Also we can control the position paleovalleys zinc and bauxite mineralization area and alluvial deposits include uranium mineralization valleys infiltration type and placer gold.

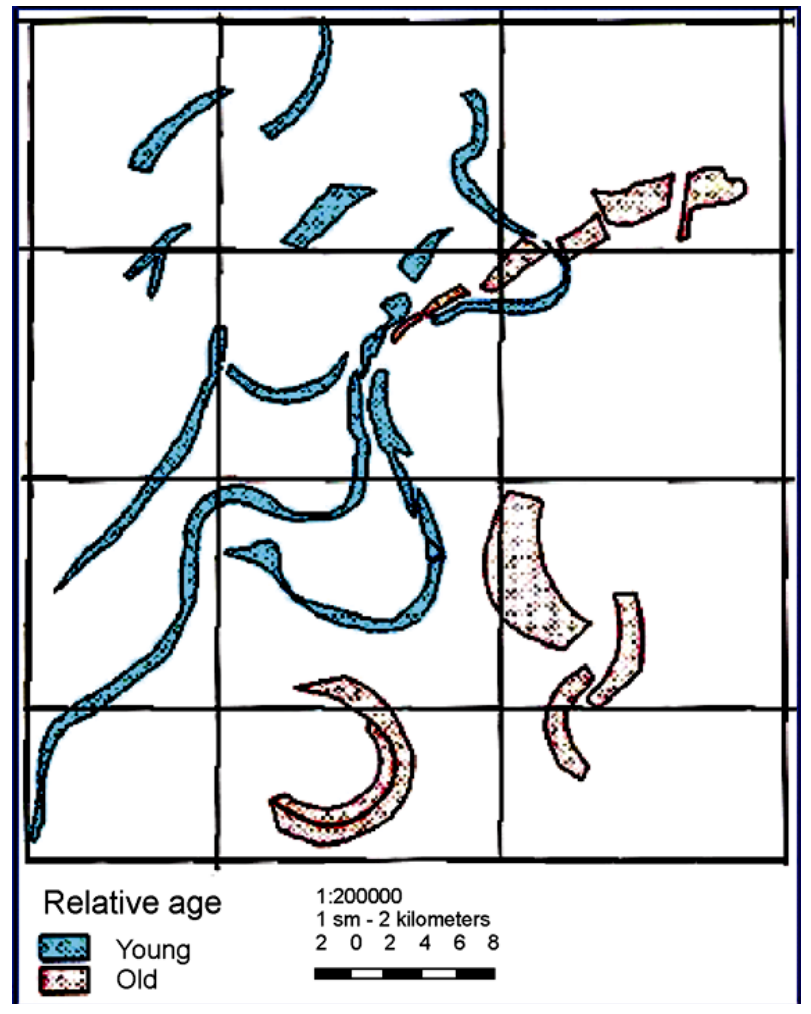

Figure 3. Scheme of buried paleovalleys

Direction paleovalleys choppy, but in general they have a northeast orientation, which is controlled by tectonic zones of the foundation. These zones are defined as the burial place themselves paleovalleys and position of karst cavities in areas interfacing with other structures orientation. The association of mineralization to the caverns in the beds paleovalleys could generally present conditions of formation of mineralization and carry it to the «Niagara» type. The term is obviously best reflects the mechanism of formation of these ores (Figure 4).

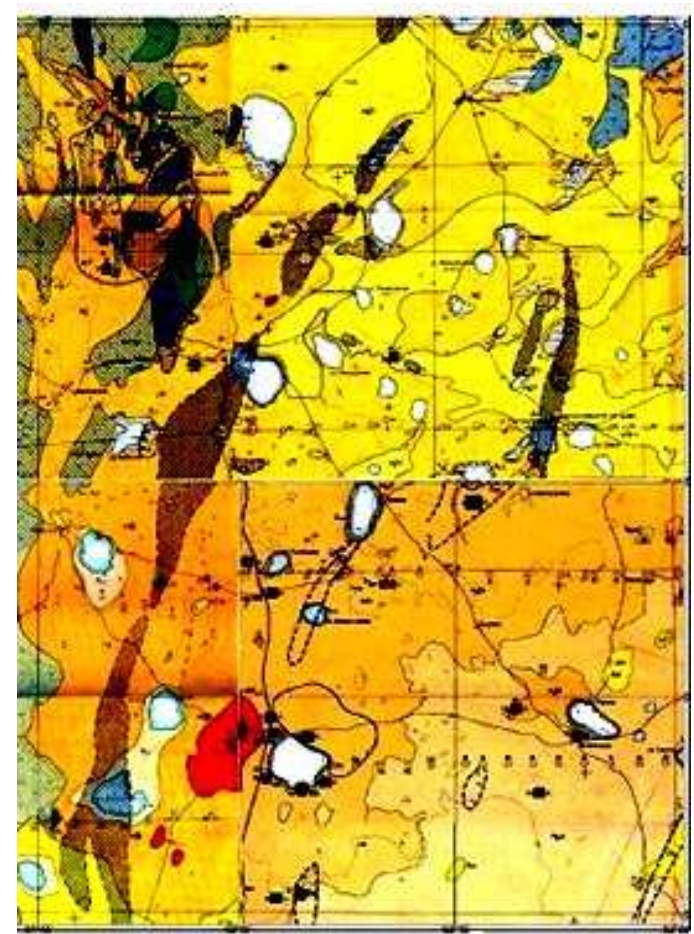

a

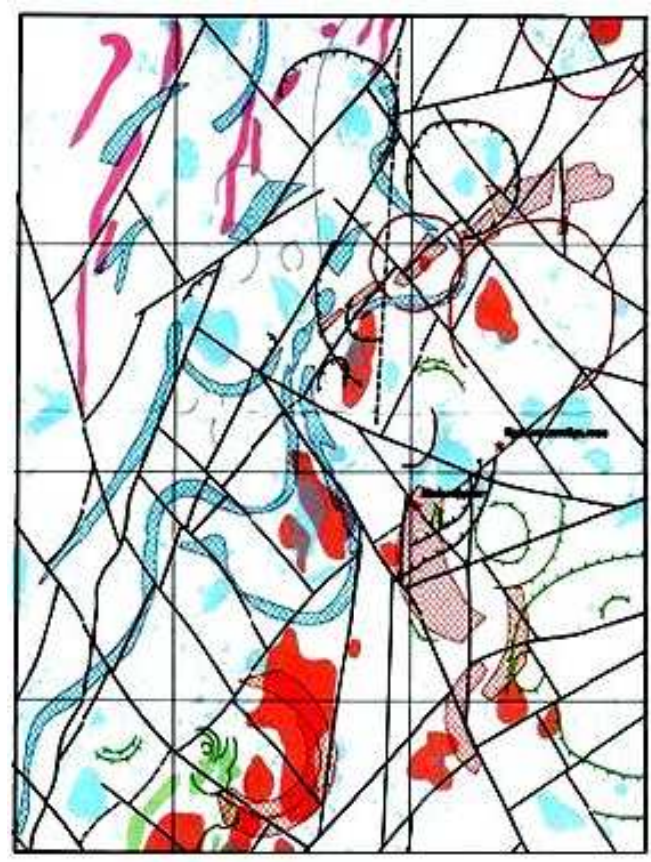

$b$

Figure 4. Geological map (a), cosmic structure scheme $(b)$

\section{CONCLUSIONS}

As a result of this work is obtained cosmological structural scheme scale 1:200 000. This area is characterized by extremely 
difficult nature conditions of reference works - in terms of predictive-manifestation of search criteria. There are extremely low openness, weakly dissected topography, and significant areas of allochthonous sediments, very high agro and technogenic "noisiness" and extensive development of water objects. Mineralization is controlled by the position of one side development of paleovalleys, and on the other side are the tectonic zones of the foundation.These zones were determined place of burial paleovalleys and the position of karst cavities in areas conjugation of divergent structures. Alluvial deposits of paleovalleys may include ore formations and significant resources of groundwater as drinking water and for industrial purposes.

\section{REFERENCES}

Baibatsha, A., 2012. Geological structure and geodynamical development of Kazakhstan territory. $34^{\text {th }}$ International Geological Congress. Brisbane, pp. 476.

Uzhkenov, B., 2002. Deep structure and mineral resources of Kazakhstan. Deep structure and geodynamics. Nauka, Almaty, Vol. 1. pp. 224.

Abdullin, A.A., 1984. Geology and Mineral Resources of South-East and North Turgay trough Ulytau. Nauka, Alma-Ata, Vol. 2. pp. 200.

Pertsova, A.V., 2000. Aerospace methods of geological research. VSEGEI, St. Petersburg, pp. 316.

Potseluyev, A.A., Ananev, Y.S., Zhitkov, V.G., 2011. Remote methods of geological research, forecasting and exploration of mineral deposits: a textbook for high schools. STT, Tomsk, pp. 304.

Tyuflin S., 1995. Construction of the digital terrain video and photomodelsby the photometric information of space images. Geodesy and cartography. 4, pp. 32-38. 